\title{
Expansão capitalista e transnacionalização do capital: o poder global das corporações empresariais e a especificidade do caso brasileiro recente
}

\section{Capitalist expansion and transnationalization of capital: the global power of business corporations and specificity of the recent Brazilian case}

\author{
Michelangelo Marques Torres \\ Mestre em Sociologia (UNICAMP) \\ Professor do Centro Estadual de Educação Tecnológica Paula Souza \\ michel1848@yahoo.com.br
}

\begin{abstract}
Resumo:
No bojo das recentes dimensões da reestruturação produtiva do capital e da reengenharia empresarial corporativa, as corporações capitalistas brasileiras parecem ganhar visibilidade no campo econômico latino-americano. O presente artigo procura investigar o campo das corporações transnacionais brasileiras inseridas numa lógica subordinada, de concentração e centralização internacional burguesa.
\end{abstract}

Palavras-chave: Imperialismo. Empresas transnacionais. Burguesia. Hegemonia.

\begin{abstract}
:
Amid the recent dimensions of productive restructuring of capital and corporate reengineering, capitalist corporations in Brazil seem to gain visibility in Latin American economic field. This paper investigates the field of transnational corporation sin Brazil entered a conditional logic of bourgeois international concentration and centralization.
\end{abstract}

Keywords: Imperialism. Transnational corporations. Bougeoisie. Hegemony.

Originais recebidos em: 18/05/2012

Aceito para publicação em: 04/10/2012

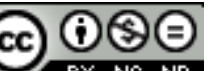

Comercial-Vedada a criação de obras derivadas 3.0 Unported License. 


\section{Introdução}

O texto que se segue tem por objetivo indicar alguns traços constitutivos da expansão capitalista no Brasil e da hegemonia das corporações empresariais transnacionais, no bojo das transformações globais em curso e das dimensões da reestruturação produtiva e da reengenharia empresarial. As questões aqui tratadas resultam de um capítulo da dissertação do mestrado que realizamos no Programa de Pós-Graduação em Sociologia da Faculdade de Filosofia e Ciências Humanas da Unicamp, intitulada Cidadania do Capital?: a intervenção social das corporações empresariais no Brasil, sob orientação do Prof. Dr. Ricardo Antunes.

O mundo contemporâneo é marcado por crises e profundas transformações em escala global. O desenho analítico por meio do qual procede a presente investigação parte do entendimento, verificado por meio de análise, segundo o qual o mundo empresarial compreende, numa mesma perspectiva, o mundo do trabalho. ${ }^{1}$ A nova morfologia do trabalho tem implicado um desenho multifacetado da dinâmica de atuação das corporações capitalistas, combinando deslocalização espacial com centralização de capital, terceirização com liofilização organizativa, ${ }^{2}$ medidas "participativas" e colaboracionistas com exploração e precarização social, produção fluida e flexível com intensificação do trabalho. De um lado, o crescimento exponencial da riqueza produzida, a partir do engendramento de infinitas possibilidades materiais e novos recursos à disposição da humanidade num ritmo acelerado sem precedentes na história; por outro lado, a concentração do poder social das empresas e da precarização do trabalho. Tais traços gerais acentuam a hipótese de uma dominação do sistema do capital na contemporaneidade, a partir do prisma da centralidade ontológica do trabalho e da determinação contingencial do capital.

Com o advento da mundialização financeira e da construção de redes de comunicação em escala global, as estratégias dos negócios capitalistas se "modernizaram". Cada vez mais as empresas se atentam e se especializam tecnicamente em suas transações com o mercado, com os "parceiros", acionistas e investidores institucionais - com destaque para os fundos de pensão e grupos de seguros

\footnotetext{
${ }^{1}$ Não é gratuito o fato de que o empresariado em geral e os eventos organizados pelas elites empresariais, bem como a literatura dominante sobre o tema, operem uma disjuntiva entre universo do trabalho (custos de produção) e universo empresarial (gestão dos negócios).

${ }^{2}$ O processo de liofilização organizativa da "empresa enxuta" e flexível é utilizado por Castillo (1996) e Antunes (2005) para se referir à redução da força de trabalho e significa eliminação, transferência, terceirização e enxugamento de unidades produtivas.
} 
(SAUVIAT, 2005; BERNARDO e PEREIRA, 2008) -, fornecedores, produtores, distribuidores e consumidores em uma rede de interdependência, configurando uma "governança corporativa". Emergem nesse cenário as denominadas "empresas-rede", interligadas pelas tecnologias de informação e telecomunicações. Trata-se de um redesenho corporativo-industrial-financeiro transnacional, sob a lógica da globalização e da terceirização no bojo do processo neoliberal.

Como consequência histórica desse processo, produziu-se, enquanto mecanismo de regulação dessa nova fase do capitalismo, encabeçados pelas instituições corporativas do capital, a expansão da reestruturação das forças produtivas, bem como a ampliação do fenômeno da financeirização e da mundialização do capital. Por mundialização do capital $^{3}$, Chesnais (1996) compreende uma nova configuração do capitalismo e de sua fase de internacionalização e valorização do capital, marcado pela sua hegemonia e pensamento único, crescente financeirização, credibilidade do sistema financeiro mundial, centralização do capital a partir de oligopólios, imposição de ajustes estruturais em favor de investidores financeiros internacionais e reconcentração de renda mundial. Tais traços evidenciam o caráter excludente e destrutivo do capital no seu estágio em curso.

Enquanto resposta a tal configuração internacional, em decorrência do alargamento dos déficits públicos e da crise de acumulação, a reorganização do capital desencadeou uma longa onda de privatização do Estado, desmontagem do setor produtivo estatal, flexibilização e desregulamentação do trabalho, com tendência à precarização estrutural $^{4}$ e novas modalidades de intensificação do trabalho (toyotismo) marcas da governança neoliberal. Os ajustes estruturais do mercado e do Estado (via reforma política) à governança global neoliberal (identificado por muitos autores como servidão financeira) são traços específicos do novo padrão de acumulação no emergente estágio do capitalismo, a partir do Consenso de Washington. Em âmbito global, uma série de reformas neoliberais são paulatinamente implementadas, com intenso corte nos gastos sociais e flexibilização da proteção universal de direitos sociais.

3 Para uma discussão mais aprofundada ver A Mundialização do Capital (Chesnais, 1996).

4 Indicamos aqui a pesquisa "Riqueza e miséria do trabalho no Brasil", disponível em Antunes (2006). Para não nos restringirmos aos países periféricos do capitalismo, como é o caso brasileiro, a tendência à precarização do trabalho e à desigualdade corresponde a um traço estrutural constitutivo inclusive da maior economia mundial: a norte-americana. Ver recente pesquisa Os sentidos das precariedades em dois mercados nacionais de trabalho: Brasil e Estados Unidos, uma comparação, disponível em: http://www.eco.unicamp.br/docprod/downarq.php?id=3094\&tp=a (acesso em: 11/05/2011). 
Em relação à submissão ao projeto neoliberal, João Bernardo (2000) compreende que a transnacionalização do capital corresponde a um processo concomitante de fragmentação dos trabalhadores e suas lutas sociais, inclusive o movimento sindical. De tal modo que os principais aspectos sociais da fragmentação de classe parecem ser "[...] o desenvolvimento, por um lado, de uma subproletarização tardia, e, por outro, do desemprego estrutural. É uma das principais características do novo perfil do mundo do trabalho sob a mundialização do capital, que apresenta provocações para o trabalho assalariado organizado" (ALVES, 2010:74-5).

Diante desse quadro, é preciso atentar para os traços globais de concentração e centralização de capitais e do poder social corporativo das transnacionais no recente período de expansão capitalista marcado por um novo estágio do imperialismo. É o que indicaremos adiante.

\section{Concentração e centralização de capitais: contexto de poder social corporativo}

Segundo Castells (1999), o modelo corporativo das "modernas empresas horizontais" consiste em sete tendências: 1) organização em torno do processo, não da tarefa; 2) hierarquia horizontal; 3) gerenciamento em equipe; 4) medida do desempenho pela satisfação do cliente; 5) maximização dos contatos com fornecedores e clientes; 6) recompensa com base no desempenho da equipe; 7) informação, treinamento e retreinamento de funcionários em todos os níveis. Tal modelo "enxuto", conforme entendemos, compreende a redução do número de funcionários (de custos com a força de trabalho) mediante automação e terceirização (contenção de custos sociais). Atuam, portanto, em rede, apoiando-se em três estratégias diferentes de internacionalização de suas atividades: a) empresas investem no exterior a partir de múltiplos mercados domésticos (investimento estrangeiro direto e tradicional); b) organiza diferentes funções da empresa, num mercado global, em localidades diferentes e articuladas; c) formação de redes internacionais interconectadas.

No quadro mundial, a influência social das corporações transnacionais revela-se um poder de intervenção global. ${ }^{5}$ Um recente estudo do ETH (Instituto Federal Suíço

\footnotetext{
${ }^{5}$ Sobre a organização das corporações empresariais e seu poder mundial, indicamos o documentário The Corporation: the Pathological Pursuitof Profit and Power (2004). A respeito do funcionamento 
de Pesquisa Tecnológica), publicado como The Network of Global Corporate Control (VITALI, GLATTFELDER, BATTISTON, 2011), identificou a rede das organizações empresariais mais poderosas no planeta, em sua maioria bancos, empresas de seguros e grandes grupos industriais. ${ }^{6} \mathrm{O}$ estudo parte da análise de 43 mil empresas transnacionais, apontando que 1318 empresas formam o núcleo da economia mundial, que além de deter o controle de mais da metade do total de vendas realizadas em todo o planeta, concentram, em conjunto, a maioria das ações de empresas espalhadas pelo mundo. Em termos metodológicos, "selecionaram 43 mil corporações no banco de dados Orbis 2007 de 30 milhões de empresas, e passaram a estudar como se relacionam: o peso econômico de cada entidade, a sua rede de conexões, os fluxos financeiros, e em que empresas têm participações que permitem controle indireto" (DOWBOR, 2011).

Segundo o recente artigo de Dowbor (2012, p.24):

As corporações formam uma gigantesca estrutura em rede, em que grande parte do controle flui para um núcleo pequeno e fortemente articulado de instituições financeiras, que, por sua vez, exerce um poder muito maior do que se poderia supor com base em sua riqueza.

Algumas das maiores corporações operam um fluxo superior ao Produto Inerno Bruto (PIB) de numerosos países: trata-se de um controle corporativo, evidenciado por uma estrutura de rede concentrativa de gigantes corporações transnacionais. Quando a referida pesquisa restringe a ligação entre os grandes grupos empresariais,

Em geral, nas principais cadeias produtivas, a corrida [concorrência] termina quando sobram poucas empresas, que em vez de guerrear, descobrem que é mais conveniente se articularem e trabalharem juntas, para o bem delas e dos seus acionistas. Não necessariamente, como é óbvio, para o bem da sociedade. (DOWBOR, 2011).

Assim, a pesquisa revela que as grandes corporações detêm um poder mundial, conforme revela a concentração corporativa no quadro a seguir: ${ }^{7}$

corporativo do sistema financeiro em crise, há o documentário Inside Job (2010), cujo título em português foi publicado como Trabalho Interno.

${ }^{6}$ Uma síntese dos resultados da referida pesquisa foi recentemente publicado por DOWBOR (2012).

${ }^{7}$ Exemplo de algumas conexões financeiras internacionais. Em vermelho, grupos europeus, em azul estão os norte-americanos, outros países estão marcados em verde. A dominância dos dois primeiros é evidente, e muito ligada à crise financeira atual. Fonte Vitali, Glattfelder e Fattiston (2011): http://jnode.blogspot.com/2011/10/network-of-global-corporate-control.html.

Em Debat: Rev. Dig., ISSNe 1980-3532, Florianópolis, n. 7, p. 45-62, jan-jul, 2012. 


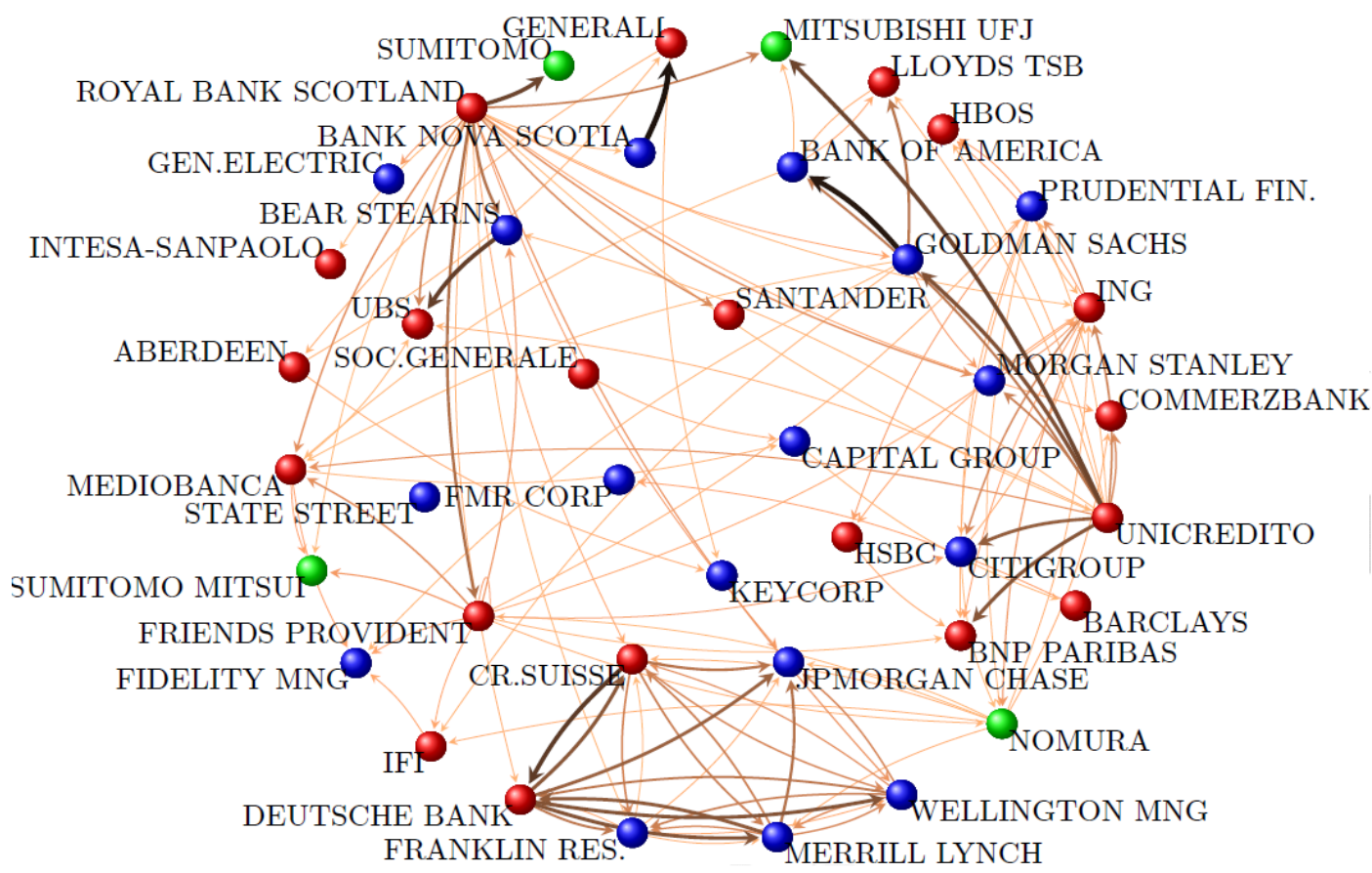

O quadro revela ampla concentração de uma rede corporativa transnacional de grupos norte-americanos e europeus, respectivamente. A participação do poder econômico nas ações das empresas imprime a capacidade de fazer prevalecer o poder acionário nas estratégias dos negócios empresariais. Segundo aponta o estudo, as organizações mais conectadas à rede concentram maior participação acionária, isto é, revela a concentração do poder e controle acionário. Como demonstra o comentário e a passagem citada por Dowbor:

O cálculo consistiu em identificar qual a fração de atores no topo que detém mais de $80 \%$ do controle de toda a rede. Os resultados são fortes: "Encontramos que apenas 737 dos principais atores (top-holders) acumulam $80 \%$ do controle sobre o valor de todas as empresas transnacionais (ETN)... Isto significa que o controle em rede (network control) é distribuído de maneira muito mais desigual do que a riqueza. Em particular, os atores no topo detêm um controle dez vezes maior do que o que poderia se esperar baseado na sua riqueza. (DOWBOR, 2011).

Ainda comentando tal estudo, Dowbor ressalta: "Quando os cientistas desfizeram o emaranhado dessa rede de propriedades cruzadas, eles identificaram uma "super-entidade" de 147 empresas intimamente inter-relacionadas que controla $40 \%$ da riqueza total daquele primeiro núcleo central de 1.318 empresas” (DOWBOR, 2011), onde menos de $1 \%$ das companhias controla $40 \%$ da rede inteira. Dessas "superentidades", 50 estão interligadas umas as outras, em rede, principalmente instituições 
financeiras, ${ }^{8}$ as quais constituem cerca de $3 / 4$ do total desse seletivo grupo. Trata-se de uma concentração de poder jamais vista na história, num momento em que o capital nunca esteve tão mundializado. Segundo um dos pesquisadores responsáveis, "Com efeito, menos de $1 \%$ das empresas consegue controlar $40 \%$ de toda a rede" (GLATTFELDER apud DOWBOR, 2011). Tais evidências reforçam a importância dos gestores do capital, uma vez que no capitalismo contemporâneo, os gestores controlam a aplicação de gigantescos recursos (muito além de qualquer capacidade racional de gestão) a partir dos grandes grupos transnacionais interconectados.

Conforme observava Boron, com base em outros dados no início deste século:

A retórica dos ideólogos da globalização neoliberal não consegue dissimular o fato de que $96 \%$ dessas duzentas empresas globais e transnacionais têm suas casas matrizes em oito países, estão legalmente inscritas nos registros de sociedades anônimas de oito países, e suas diretorias têm sua sede em oito países do capitalismo metropolitano (...) Seu alcance é global, mas sua propriedade e seus proprietários têm uma clara base nacional (BORON, 2002, p. 50).

Por outras palavras, apesar da fusão de interesses globais representadas pelo grande capital, "hoje, inclusive, ainda que seja difícil falar em nacionalidade do capital, efetivamente há um enorme peso do capital noter-americano em todas as atividades mais importantes, mais dinâmicas e com maior futuro no mundo" (COCEÑA, 2010, p. 218).

Os valores financeiros e especulativos do grande capital chegam a atingir a faixa de 14 vezes o PIB mundial (DOWBOR, 2011). O contexto expansivo de liberação de fluxos financeiros e de bens e serviços entre os países, acompanhado pelo avanço comunicacional e desenvolvimento tecnológico em escala global, contribui para o engrandecimento das grandes corporações transnacionais (POCHMANN, 2011). Com a intensificação do movimento de concentração e centralização do capital forjado no neoliberalismo, reforça-se o poder privado, sobretudo pós Consenso de Washington e do primado do Banco Mundial e do FMI. Contudo, no arranjo de crise internacional de 2007-2008, o centro dinâmico do capitalismo passa a ser redesenhado numa disputa intercapitalista (HARVEY, 2011).

Conforme indaga o economista da Unicamp/Ipea, trata-se de um processo de hipermonopolização do capital sem precedentes:

\footnotetext{
${ }^{8}$ As principais são Barclay, JP Morgan, Merrill Lynch, Goldman Sachs, Morgan Stanley e companhias de seguros e bancos franceses como Axa, Natixis, Sociétégénérale, el grupo Banque populaire-Caisse d'épargne o BNP-Paribas.
}

Em Debat: Rev. Dig., ISSNe 1980-3532, Florianópolis, n. 7, p. 45-62, jan-jul, 2012. 
$\mathrm{O}$ que se poderia esperar quando cerca de metade da riqueza do mundo e quatro quintos dos investimentos em pesquisa e desenvolvimento tecnológico são de responsabilidade das quinhentas maiores corporações transnacionais? Elas governam o mundo, pois se tornaram tão grandes que não podem mais nem sequer quebrar. Além disso, corporações são cada vez mais dependentes da associação com o Estado Nacional, sugando, como carrapatos, parcela crescente do orçamento público (POCHMANN, 2011, p. 7).

Convergindo com esse diagnóstico, a super concentração do poder financeiro mundial pode ser indicada pela estimativa de que apenas quatro dos maiores bancos norte-americanos (JP Morgan, Citibank, Bank of America e Goldman Sachs) controlam $94,4 \%$ dos derivados financeiros. Segundo relatório trimestral do Office of the Currency Controlle, dos 25 maiores bancos comerciais, 4 bancos detêm $94.4 \%{ }^{9}$ (250 trilhões de dólares) do valor nominal bruto em contratos derivativos.

Os $2 \%$ adultos mais ricos do mundo possuem a metade da riqueza global, enquanto a parcela correspondente a apenas $1 \%$ da população adulta detém $40 \%$ dos ativos mundiais. Em contrapartida, a metade mais pobre da população adulta só possui 1\% da riqueza global" (COSTA, 2008, p. 109).

Conforme divulgação de pesquisa, apenas $2,4 \%$ das famílias detém $33 \%$ da riqueza no Brasil (Folha de São Paulo, 02/04/2004) e 218 milhões de crianças são aliciadas pelo trabalho infantil (ALVES, 2010). De acordo com os dados da Organização Internacional do Trabalho (OIT), 1/3 da força humana mundial disponível ao trabalho exerce trabalhos parciais, precários, temporários ou vivencia o desemprego. Só nos países industriais desenvolvidos, 40 milhões estão desempregados (ALVES, 2010). Se focalizarmos os indicadores relativos ao denominado "países do terceiro mundo", representativos de $2 / 3$ dos trabalhadores mundiais, a situação se agrava. Contraditoriamente, o sistema mundial remunera mais os especuladores do que os produtores (DOWBOR, 2009).

O relatório Unctad ${ }^{10} 1997$ já destacava o aumento da concentração de renda no planeta nas últimas três décadas. Também o Unctad-98 ressaltou temas de parcerias para o desenvolvimento, reunindo governos, empresas e organizações da sociedade civil na busca de novas articulações. Curiosamente, apenas no Brasil, de 1996 a 2005 houve um crescimento em $215,1 \%$ de fundações privadas e associações sem fins lucrativos.

Além de controlarem diversos setores da economia mundial, as corporações empresariais influenciam fortemente as políticas governamentais. "Somente a General

9 Disponível em: www.zerohedge.com/news/five-banks-account-96-250-trillion-outstanding-derivativeexposure-morgan-stanley-sitting-fx-de (consultado em out. 2011).

10 United Nations Conference on Trade and Development, órgão internacional que tem por objetivo promover a integração favorável ao desenvolvimento dos países em desenvolvimento na economia mundial, por meio de fóruns intergovernamentais, divulgação de dados internacionais e cooperação com diferentes organizações e países.

Em Debat: Rev. Dig., ISSNe 1980-3532, Florianópolis, n. 7, p. 45-62, jan-jul, 2012. 
Motors tem um volume de negócios anual maior que os 48 países menos avançados” (Toussaint apud COSTA, 2008:116). Apenas as seis maiores empresas transnacionais não financeiras, no ano de 2000, detinham um volume de negócios superior ao PIB brasileiro. De acordo com a mesma fonte, as corporações transnacionais controlam ainda cerca de $70 \%$ do comércio mundial.

Trata-se de um processo que Costa $(1993 ; 2008)$ identificou por "quadro de remonopolização global da burguesia" hierarquizada a partir de seu pólo hegemônico financeiro, processo iniciado pelo desenvolvimento acelerado de fusões e aquisições empresariais na economia mundializada. De tal forma que as corporações transnacionais capitalistas passam a atuar a partir de padrões mundiais de planejamento, organização da produção, sistema de recursos humanos e normas administrativas. Assim, as diferentes frações da burguesia buscam redefinir os seus pesos no mercado mundial, mediante a concorrência intercapitalista, ${ }^{11}$ que ganha novos contornos.

Enfatizando a competição mundial entre os capitais e a intensificação da exploração do trabalho, Bihr destaca que:

No plano econômico, a réplica capitalista à luta do proletariado contra sua exploração tem sido sempre de aumentar a intensidade e mais ainda a produtividade do trabalho, desenvolvendo os meios de produção com o objetivo de aumentar a mais-valia relativa. E é pelo mesmo caminho que o conduz à concorrência entre os capitais particulares, única possibilidade, para determinado capital, de realizar uma taxa de lucro superior à taxa média, que é em última análise de aumentar, ainda neste caso, a produtividade do trabalho (BIHR, 1998, p.127).

Nessa nova fase do imperialismo, "com a internacionalização da produção e a mundialização da economia, as corporações transnacionais conseguiram unificar globalmente o ciclo do capital: produzem internacionalmente, financiam-se internacionalmente e realizam a produção também internacionalmente" (COSTA, 2008, p. 95), além de deslocarem para os países periféricos grande parte da criação do valor, como aponta Michalet (1984). Tudo isso no bojo de um processo de desconcentração das fábricas que, dada a transnacionalização do capital e as novas tecnologias da informação e a microeletrônica, requer "aumento das atividades de trabalho produtivo realizado no espaço domiciliar ou em pequenas unidades produtivas, conectadas ou integradas às empresas" (ANTUNES, 2005, p. 80). A seguir, procuraremos traçar uma

11 Em Esboço de uma crítica da Economia Política, texto que influenciaria (certamente com reparos) a leitura da economia política de Marx, o jovem Engels já expressara que "O confronto de capital contra capital, de trabalho contra trabalho, de propriedade contra propriedade, lança a produção num ardor febril que subverte completamente todas as relações naturais e razoáveis. Nenhum capital pode enfrentar a concorrência de outro se não se elevar a seu mais alto nível de atividade (ENGELS, 1981:72). 
breve análise do contexto de expansão capitalista no brasil contemporâneo, atentandonos para sua inserção subordinada ao grande capital internacional (capital-imperialismo, como denomina Virgínia Fontes) e a mediação do governo com as corporações transnacionais.

\section{Transnacionais e subimperialismo: a expansão capitalista no Brasil}

É notório o fato de que as corporações capitalistas no Brasil estão num contexto de constante expansão e de internacionalização. Neste sentido,

O Brasil está em terceiro lugar no ranking das 100 empresas de países "emergentes" com potencial para desafiar empresas transnacionais estadunidenses e europeias. Juntas, as 100 empresas somam US\$ 1,5 trilhão. São 14 as empresas com origem no Brasil, somente atrás de empresas da China e Índia. Entre as brasileiras, estão Petrobras, Vale e as grandes construtoras. Somente a empresa Camargo Corrêa dobrou de tamanho entre 2005 e 2007, somando US\$ 6,4 bilhões em 2007 (GARCIA, 2010, p. 11).

O modelo de desenvolvimento capitalista em que o Brasil está submetido, ao mesmo tempo em que submete o conjunto dos outros países latino-americano, o insere num quadro global de modo dependente e subordinado. De tal modo que

o Brasil integra hoje um grupo de países que ascenderam a uma tal concentração de capitais que os impele - ainda que de maneira subordinada a se incorporar ao conjunto dos países imperialistas. Ainda que sendo 'os últimos dos primeiros', nos colocam diante de urgentes desafios" (FONTES, 2010b, p.223).

De acordo com a revista Fortune e a revista América Economía, a lista das 500 maiores empresas do mundo, assim como a das 500 maiores empresa da América, há uma escassa participação de empresas latino-americanas nas atividades de maior destaque, com exceção da Odebrecht, Aracruz e Votorantim (CECEÑA 2010).

O quadro brasileiro, amplamente inserido no processo de transnacionalização, delineia-se permeado por contradições e caminhos não lineares. A última década pode ser registrada como expansão capitalista brasileira. No entanto, é marcante a sua inserção subordinada ao mercado global (dependência estrutural da economia brasileira). Os recentes esforços governistas de atenção à burguesia industrial, a exemplo de estímulos ao setor como redução de impostos, programa PAC (Plano de Aceleração do Crescimento) e difusão de crédito contribuem para o mercado interno, ao mesmo tempo em que estimula a transnacionalização de capitais no país (FONTES, 2010). Trata-se de um movimento de expansão do capital. Em relação à exportação de capital como investimento estrangeiro direto (IED), “em 2006, pela primeira vez, os 
fluxos externos de IED ultrapassaram os influxos de IED, sinal de que as empresas brasileiras estão aprofundando seu compromisso para se tornar empresas globais" (RAMSEY e ALMEIDA, 2009, p. 15).

Apesar dos laços de dependência e subordinação internacionais, a última década demonstra maior diversificação das relações comerciais e diplomáticas (política externa) no país. Quanto aos arranjos do bloco no poder podemos indicar, apesar dos limites do presente trabalho, a influência do capital financeiro, do agronegócio, das transnacionais (de diversos setores, a despeito de ser nacional ou estrangeira) e dos Fundos de Pensão. Apenas em 2010, o BNDES concedeu créditos no volume de US\$ 96,32 bilhões, o que corresponde a 3,3 vezes mais que o valor concedido pelo Banco Mundial no mesmo período (LIMA, 2012, p. 6). Segundo a mesma fonte, 13 empresas do Brasil agregam a relação de "global challengers": Camargo Corrêa, Coteminas, Embraer, Gerdau, JBS-Friboi, Marcopolo, Natura, Odebrecht, Brasil Foods, Petrobras, Magnesita, Vororantim e WEG (é notável, nessa lista, a presença de corporações parceiras da Comunitas e do GIFE). Apenas a China e a Índia estão à frente do Brasil, com 33 e 20 empresas, respectivamente. Conforme reportagem:

Os bancos e entidades financeiras também têm se expandido para fora. Em
2010 , o Banco do Brasil comprou o controle acionário do Banco Patagonia, o
sexto maior da Argentina, por 479,6 milhões de dólares. Além disso,
Bradesco e BB assinaram um memorando de entendimentos com o português
Banco Espírito Santo para iniciar atividades no continente africano. (...)
segundo o último censo do Banco Central, o estoque total de ativos no
exterior foi de 274,6 bilhões de dólares em 2010 ( $23 \%$ a mais que em 2009 ),
e o total de investimentos brasileiros diretos no exterior (IBD) atingiram
189,2 bilhões (mais que o triplo levantado em 2001, que totalizava 49,7
bilhões). (LIMA, 2012, p. 6).

Os quadros gerenciais da gestão administrativa das transnacionais brasileiras estão inseridas num processo de visão mundial dos negócios da empresa.

Contudo, estamos tratando de um processo histórico em curso, por isso procuramos evidenciar apenas alguns traços centrais do diagnóstico mundial do poder social das corporações empresariais transnacionais, o qual conforma a inserção subordinada (apesar da expansão do capitalismo brasileiro) do quadro nacional. Uma avaliação mais extensa nesse aspecto está fora do escopo deste artigo. Tal quadro conforma os investimentos, planejamento e inovações empresariais numa lógica de reprodução ampliada das relações capitalistas.

Considerando a projeção externa do subimperialismo da economia sobre seus países vizinhos, destacaremos alguns casos de investimentos estratégicos do capitalimperialismo brasileiro. No Uruguai, as empresas de origem brasileira Friboi e Marfrig Em Debat: Rev. Dig., ISSNe 1980-3532, Florianópolis, n. 7, p. 45-62, jan-jul, 2012. 
monopolizam $70 \%$ da exportação de carne deste país. Na Bolívia, também se observa a expansão de capitais sediados no Brasil: "apenas 100 famílias brasileiras entre as que residem no país respondem por 35\% das exportações de soja feitas pela Bolívia, produção que se concentra praticamente no Departamento de Santa Cruz" (LUCE, 2007, p. 98).

$\mathrm{Na}$ Argentina, Pós-crise de 2000, o investimento externo direto do capital brasileiro no país permitiu a compra da Quilmes pela Ambev, a compra da maior fábrica de cimento do país, Loma Negra, pela brasileira Camargo Corrêa, e a Friboi ter se tornado o maior polo frigorífico mundial com a compra da Swift argentina - com amplo crédito do BNDES. Ou seja, o financiamento governamental tem impulsionado a expansão das transnacionais brasileiras no continente, conforme revelam Luce (2008) e Novoa (2010). Também no Peru, a Votorantim e a MinCo controlam a produção metalúrgica de zinco (principal produto mineral peruano), ao mesmo tempo em que a brasileira Gerdau adquiriu a Sider Peru (maior siderúrgica do país) e a Petrobras/Pecom detém a segunda produção de petróleo.

O investimento das transnacionais brasileiras em outros países é significativo. A Vale, por exemplo, atua em 34 países, tornando-se a "maior gigante de mineração mundial" (FONTES, 2010). A Coteminas realizou uma fusão com a americana Springs, tornando-se a maior produtora mundial de cama, mesa e banho, concentrando-se na Argentina, Brasil e México, por terem custos de produção e mão de obra mais baixos.

Segundo a revista Valor Econômico (2008), as 25 empresas mais internacionalizadas são: JBS-Friboi (alimentos); Odebrecht (construtora); Gerdau (Metalurgia e siderurgia); Coteminas (Têxtil e vestuário); Ibope (serviços); Vale (mineração); Sabó (veículos e peças); AMBev (bebidas); Metalfrio (eletroeletrônica); Artecola (petroquímica); Marfrig (alimentos); Gol (transporte e logística); Camargo Corrêa (grupo econômico); WEG (mecânica); Itautec (tecnologia da informação); Comex Trading (comércio exterior); Embraer; Marcopolo; Mahle Metal Leve; DHB; G Brasil (veículos e peças); Tupy (metalurgia); ALL America; TAM (transporte e logística); Petrobras (petróleo e gás).

Tal realocação dos negócios capitalistas brasileiros demonstra que foram impulsionados pela abertura de mercados, desregulamentação e flexibilização oriundas do desmonte neoliberal no país, a partir dos anos 1990. O próprio neoliberalismo vem sendo criticado por parcela significativa da sociedade, incluindo uma parcela do empresariado e de intelectuais associados ao capital, num contexto de sustentação de 
um novo modelo de desenvolvimento para o país, no qual o Estado assumiu papel central na convivência harmônica com o mercado, a exemplo do denominado "neodesenvolvimentismo" emergente no período de pós-reformas orientadas para o mercado. Aqui, é preciso mencionar que há um movimento ideológico, já incorporado no interior de parte da esquerda e do empresariado, de que o atual governo seria de cunho "neodesenvolvimentista". Segundo essa linha de análise, o Brasil estaria caminhando para se constituir numa nova potência que ditaria os rumos internos devido a sua inserção privilegiada na economia internacional em crise, apresentando grande crescimento interno. Não obstante, as grandes obras sustentadas pela aliança Estadocorporações empresarias, ${ }^{12}$ a exemplo do PAC, infraestrutura para Olimpíadas e Copa do Mundo etc., não devem ser entendidas nesse sentido. A real condição dependente e subalterna do capitalismo brasileiro ao grande capital imperialista questiona tais fundamentos ideológicos.

A manutenção do atual governo faz-se fundamental para a conciliação de classe promovida ao longo da última década. A despeito de conflitos evidentes, o empresariado encontrou no governo Lula um ponto de apoio, uma direção. ${ }^{13}$ O governo Lula manteve ao mesmo tempo em que reformou o neoliberalismo no Brasil, configurando uma nova etapa do neoliberalismo e uma reconfiguração das forças sociais em disputa. Sua política de pequenas concessões (e a herança histórica de seu partido) fez com que as lideranças dos movimentos sociais se aproximassem do governo, ampliando políticas sociais compensatórias e promovendo reforma na legislação sindical (sob concessão de poder às direções das centrais sindicais ${ }^{14}$ - as quais se demonstraram acomodadas ${ }^{15}$ - e fundos financeiros). Trata-se de um

\footnotetext{
${ }^{12}$ Vale a menção à Lei de Inovação, que dentre outras medidas abre brechas para o Estado subsidiar o setor privado, além das empresas conseguirem abatimento no Imposto de Renda devido investimento em pesquisa e desenvolvimento.

${ }^{13}$ Já no início dos anos 1990, no governo Itamar Franco (que assumiu a Presidência após a conturbada saída de Collor), o empresariado reivindicava o apoio do Estado à sua agenda social, sendo expressiva a Carta do PNBE enviada ao presidente, a qual mencionava buscar "substituir a visão empresarial corporativa retrógrada" associada a "uma efetiva cidadania dos diversos grupos sociais, em que um Estado coordenador dos anseios da sociedade - e não o seu tutor - compartilha a responsabilidade, quanto aos rumos da sociedade, com seus segmentos representativos" (PNBE. Carta ao presidente Itamar Franco apud BIANCHI 2001, p. 123-4).

${ }^{14}$ Segundo Boito Jr. (2006), ao analisar o novo corporativismo e a relação da elite sindical (dirigentes) com a administração pública do governo Lula, criou-se uma "ilusão de poder no núcleo operário do novo sindicalismo", uma vez que com essa repercussão ideológica nos trabalhadores, "o novo sindicalismo 'imagina' ter chegado ao poder".

${ }^{15}$ Apesar da acomodação política na cúpula, o ativismo sindical de base perdurou. Vale lembrar o crescimento e concorrência das centrais sindicais, que se ampliaram a partir de 2004. Além da Força Sindical e da CUT, ocorreu a fusão / divisão de correntes sindicais: Conlutas, Intersindical, NCST (Nova Central Sindical de Trabalhadores), UGT (União Geral dos Trabalhadores), CTB (Central dos
} 
reformismo, pautado por medidas flexibilizantes apesar do discurso protecionista (BOITO, GALVÃO, MARCELINO, 2009). “O governo Lula foi o reformismo da governabilidade do regime democrático liberal", um reformismo quase sem reformas, afirma Arcary (2011, p. 23). O fato é que o governo Lula sequer desafiou o domínio empresarial sobre a sociedade brasileira. As constatações a que chegamos permitem afirmar que o Estado brasileiro esteve a serviço das classes dominantes no período em foco, especialmente o capital internacional, ${ }^{16}$ o que refuta qualquer perspectiva de potencialidade emancipatória do PT. A liberação dos transgênicos, os financiamentos do BNDES e a construção de Belo Monte são bons exemplos disso. É imprescindível observarmos que, ao mesmo tempo, o capitalismo brasileiro absorveu concessões também à classe trabalhadora, o que implicou a reorganização da esquerda na última década. Contudo, tais desdobramentos de análise nos deslocariam do enfoque da presente pesquisa.

O governo Lula se esforçou em reforçar uma imagem de gestão que buscou recuperar a capacidade de administração pública esfacelada na gestão anterior. $\mathrm{O}$ fato é que a agenda social do empresariado parece se integrar a uma nova agenda de desenvolvimento para o país. A despeito da abertura para o empresariado ocorrida na gestão FHC, no governo Lula a presença do Estado se faz mais preponderante na agenda social. Os subsídios do BNDES às grandes empresas e a transferência de verba pública para determinados setores em que atua a iniciativa privada são fortes evidências disso. De 2007 a 2011, houve um crescimento, sem oscilações, no valor de operações com subcrédito social liberadas pelo Banco às empresas (saltando de 12 para 62 bilhões de reais).

\section{Considerações Finais}

Conforme nos esforçamos em demonstrar, a expansão do capitalismo brasileiro, marcada por um contexto global de crise que se prolonga há décadas, é relacional e envolve o arranjo político-econômico com o conjunto dos outros países e das frações de classe dominante personificadas por meio de seus gestores empresariais do grande capital. O processo de exportação de capitais brasileiros e de transnacionalização de

Trabalhadores do Brasil) - com exceção da Conlutas e Intersindical, prevalece o apoio sindical ao governo Lula.

${ }^{16}$ Se somarmos os gastos com os juros e amortizações da dívida pública durante os governos FHC e Lula (1995-2010), o valor ultrapassa os $\mathrm{R} \$ 6,8$ trilhões.

Em Debat: Rev. Dig., ISSNe 1980-3532, Florianópolis, n. 7, p. 45-62, jan-jul, 2012. 
empresas orienta-se para a América do Sul, inserindo o Brasil numa economia dinâmica e subimperialista.

A reengenharia empresarial e organizacional encampada a partir da reestruturação produtiva é, na verdade, expressão da "desmedida do capital"17, de onde advêm, inclusive, as propostas de $\mathrm{RSE}^{18}$. Portanto, é preciso lembrar a tríplice dimensão do complexo da reestruturação produtiva (ALVES 2007): inovações organizacionais, inovações tecnológicas e inovações sócio-metabólicas.

o poder social das empresas se revela ainda mais imponente no contexto neoliberal do que em qualquer período precedente (BERNARDO 2004; LINHART 2007). No contexto de expansão do poder social das empresas, sustenta-se um discurso segundo o qual a rigidez do modelo de regulação taylorista-fordista tem sido superada por modelos organizativos mais "flexíveis", apresentando o trabalho de modo mais humanizado, inclusive sem alienação. Porém as palavras não são as coisas. Trata-se de um discurso ideológico. As formas de gestão atual visam, sobretudo: a) ao controle e exploração do trabalho (no ambiente interno da empresa), que a RSE procura velar; b) à expansão do seu poder social do interior das empresas para a sociedade em geral, empreendimento em que se destacam as corporações orgânicas do capital; c) a assumir relativa autonomia na pressão do mercado capitalista (privado) sobre o Estado burguês contexto de expansão da lógica do "terceiro setor". Poder político, direção ideológica e exploração econômica parecem constituir o tripé sobre o qual as corporações empresariais procuram afirmar entre si, numa incessante concorrência e disputa intercapitalista, o primado do sistema do capital sobre o conjunto dos trabalhadores. Diante do presente contexto, o Brasil parece se tornar um "parceiro" do capitalimperialismo, na feliz expressão de Virgínia Fontes, sob a lógica da pedagogia da hegemonia (NEVES, 2005) e da direção empresarial - organizadas por determinadas corporações orgânicas do capital que se articulam em torno do financiamento e das políticas governamentais no país, sobretudo a partir do quadro desencadeado nos anos 2000.

\footnotetext{
${ }^{17}$ Trata-se de uma feliz expressão de Linhardt (2007), na linha do que Antunes (2005), destacando outros aspectos morfológicos e ontológicos da sociedade capitalista, já denominava por "desmedida empresarial".

${ }^{18}$ RSE é a sigla utilizada, na literatura de management, para as ações corporativas de Responsabilidade Social Empresarial. Remetemos basicamente ao nosso estudo desenvolvido como dissertação de mestrado anteriormente citado, aonde essa questão é tratada mais a fundo.
} 


\section{Referências bibliográficas}

ALVES, Giovanni. O novo (e precário) mundo do trabalho: reestruturação produtiva e crise do sindicalismo. $2^{\mathrm{a}}$ reimpressão, São Paulo: Boitempo, 2010.

ANTUNES, Ricardo. O caracol e sua concha: ensaios sobre a nova morfologia do trabalho. São Paulo: Boitempo, 2005.

(org.). Riqueza e miséria do trabalho no Brasil. São Paulo: Boitempo, 2006.

BERNARDO, João. Transnacionalização do capital e fragmentação dos trabalhadores: ainda há lugar para os sindicatos? São Paulo: Boitempo, 2000.

BIHR, Alain. Da Grande Noite à Alternativa: o movimento operário europeu em crise. São Paulo: Boitempo, 1998.

BOITO JR, Armando; GALVÃO, Andreia; MARCELINO, Paula. Brasil: o movimento sindical e popular na década de 2000. OSAL (Buenos Aires: CLACSO), Año 20, n.26, oct. 2009

BORÓN, Atílio. Império \& Imperialismo: uma leitura crítica de Michael Hardt e Antonio Negri. Buenos Aires, Clacso, 2002.

CASTELLS, Manuel. A sociedade em rede - A era da informação: economia, sociedade e cultura. Vol.1. São Paulo: Paz e Terra, 1999.

CASTILLO, Juan J. Sociologia del trabajo. CIS, Madri, 1996.

CECEÑA, Ana Esther. Os caminhos e os agentes do saqueio da América Latina. In: Instituto Rosa Luxemburg (org.). Empresas transnacionais brasileiras na América Latina: um debate necessário. São Paulo: Expressão Popular, 2010.

CHESNAIS, F. A mundialização do capital. São Paulo: Xamã, 1996.

COSTA, Edmilson. A Globalização e o capitalismo contemporâneo. São Paulo: Expressão Popular, 2008. 
DOWBOR, Ladislau. Hora de redirecionar os recursos. Le Monde Diplomatique. Ano 2, n.22, maio 2009.

. A rede do poder corporativo mundial. 2011 (disponível em:www.dowbor.org).

O poder corporativo dos intermediários financeiros. Le Monde

Diplomatique Brasil. Ano 2, jul / ago 2012.

DREIFUSS, René. A internacional capitalista: estratégias e táticas do empresariado transnacional 1918-1986. Rio de Janeiro: Editora Espaço e Tempo, 1986.

FONTES, Virgínia. O Brasil e o capital-imperialismo: teoria e história. Rio de Janeiro: EPSJV/ Editora UFRJ, 2010a.

. O imperialismo brasileiro. In: Instituto Rosa Luxemburg (org.). Empresas transnacionais brasileiras na América Latina: um debate necessário. São Paulo: Expressão Popular, 2010b.

HARVEY, David. O enigma do capital: e as crises do capitalismo. São Paulo: Boitempo, 2011.

LIMA, Eduardo Sales de. Ampliação do capital orienta a política externa In: jornal Brasil de Fato, ano 9, n.462, 5 a 11 de janeiro de 2012, p.6.

LUCE, Mathias. O subimperialismo revisitado: a expansão do capitalismo brasileiro e a política de integração do governo Lula da Silva na América Latina. Comunicação ao IV Colóquio Internacional de la SEPLA: América Latina - escenariosdelnuevosiglo. Nuevos desafios y horizontes de transformación, Buenos Aires, 2008.

MICHALET, Charles-Albert. Capitalismo mundial. Rio de Janeiro: Paz e Terra, 1984.

NEVES, L.M.W. (org).A nova pedagogia da hegemonia: estratégias burguesas para educar o consenso. São Paulo: Xamã, 2005.

NOVOA, Luis Fernando. O Brasil e seu “desbordamento": o papel central do BNDES na expansão das empresas transnacionais brasileiras na América do Sul. In: Instituto Rosa Luxemburg (org.). Empresas transnacionais brasileiras na América Latina: um debate necessário. São Paulo: Expressão Popular, 2010. 
POCHMANN, Márcio. Transformação do capitalismo. Le Monde Diplomatique Brasil, Ano 5, n.51, Outubro 2011.

RAMSEY, J; ALMEIDA, A. (orgs.). A ascensão das multinacionais brasileiras. Rio de Janeiro: Elsevier-Fundação Dom Cabral, 2009.

SAUVIAT, Catherine. Os fundos de pensão e os fundos mútuos: principais atores da finança mundializada e do novo poder acionário. In: Chesnais, François (org.). A finança mundializada: raízes sociais e políticas, configuração, consequências. São Paulo: Boitempo, 2005.

VITALI, S; GLATTFELDER, J.B; BATTISTON, S. The network of global corporate control.Vol.6, issue 10, Plos One, Oct. 2011 (disponível em: www.plosone.org). 